\title{
Avaliação das propriedades histológicas de enxertos meniscais humanos armazenados em banco de tecido*
}

\section{Evaluation of Histological Properties of Human Meniscal Grafts Stored in a Tissue Bank}

\author{
Alfredo dos Santos Netto ${ }^{10} \quad$ Uri Antebi ${ }^{20}$ Carolina Esteves de Morais ${ }^{3(0)}$ Leonardo Sementilli ${ }^{3(1)}$ \\ Nilson Roberto Severino ${ }^{10}$ Ricardo de Paula Leite Cury ${ }^{10}$
}

${ }^{1}$ Departamento de Ortopedia e Traumatologia, Faculdade de Ciências Médicas da Santa Casa de São Paulo, São Paulo, SP, Brasil

2 Banco de Tecidos Musculoesqueléticos, Irmandade da Santa Casa de

Endereço para correspondência Alfredo dos Santos Netto, Master Rua Doutor Cesário Mota Júnior, 112, Vila Buarque, São Paulo, SP, Misericórdia de São Paulo, São Paulo, SP, Brasil

${ }^{3}$ Anatomia Patológica, Irmandade da Santa Casa de Misericórdia de São Paulo, São Paulo, SP, Brasil

Rev Bras Ortop 2020;55(6):778-782.

\section{Resumo \\ Palavras-chave \\ - transplante \\ - menisco \\ - meniscos tibiais \\ - banco de tecidos}

Objetivos Avaliar e comparar as características histológicas de meniscos frescos e meniscos congelados armazenados em banco de tecidos por 1 mês e por 5 anos.

Métodos Foi feito um estudo histológico com enxertos meniscais. Avaliamos 10 meniscos, sendo 2 que ficaram armazenados sob congelamento por 5 anos, 4 armazenados congelados por 1 mês, e 4 frescos, recém captados. Foram feitos cortes histológicos corados com hematoxilina e eosina e Tricrômico de Masson, para avaliação das propriedades histológicas.

Resultados Os meniscos congelados por 1 mês apresentaram preservação parcial da estrutura das fibras colágenas, sem degeneração hidrópica significativa do tecido. Nos meniscos congelados por 5 anos, observamos dissociação evidente das fibras colágenas, com presença de múltiplos focos de degeneração hidrópica.

Discussão Encontramos degeneração bem mais significativa nos meniscos armazenados por 5 anos, o que indica que o longo período de congelamento leva à progressão significativa da degeneração do tecido. Isto pode sugerir que o período de 5 anos, considerado período máximo que o enxerto pode permanecer armazenado antes de ser transplantado, é um período muito longo.

Conclusão Nos enxertos armazenados por 1 mês, existiu apenas discreta alteração degenerativa das fibras colágenas, enquanto que nos meniscos com 5 anos de congelamento foi observada degeneração significativa do tecido. Tibiais
Trabalho realizado no Grupo do Joelho do Departamento de Ortopedia e Traumatologia da Irmandade da Santa Casa de Misericórdia de São Paulo - "Pavilhão Fernandinho Simonsen", São Paulo, SP, Brasil. recebido

30 de Julho de 2019

aceito

10 de Janeiro de 2020
DOI https://doi.org/

10.1055/s-0040-1709199. ISSN $0102-3616$.
Copyright $\odot 2020$ by Sociedade Brasileira License terms de Ortopedia e Traumatologia. Published by Thieme Revinter Publicações Ltda, Rio de Janeiro, Brazil 


\begin{abstract}

\section{Keywords}

- meniscus

- tibial menisci

- transplantation

- tissue bank

Objectives The present paper aims to evaluate and compare the histological features of fresh and frozen menisci stored in a tissue bank for 1 month and for 5 years.

Methods The meniscal grafts were subjected to a histological study. A total of 10 menisci were evaluated; 2 were frozen for 5 years, 4 were frozen for 1 month, and 4 were fresh, recently harvested specimens. Histological properties were evaluated in sections stained with hematoxylin and eosin and Masson trichrome methods.

Results The menisci frozen for 1 month showed partially preserved collagen fiber structure and no significant hydropic tissue degeneration. The menisci frozen for 5 years presented an evident dissociation of collagen fibers and multiple foci of hydropic degeneration.

Discussion Degeneration was much more significant in menisci stored for 5 years, indicating that a long freezing period results in substantial progression of tissue deterioration. This may suggest that the 5 -year period, considered the maximum time for graft storage before transplant, is too long.

Conclusion Grafts stored for 1 month showed a slight degenerative change in collagen fibers, whereas menisci frozen for 5 years presented significant tissue degeneration.
\end{abstract}

\section{Introdução}

Ao longo das últimas décadas, o tratamento das lesões meniscais vem evoluindo continuamente. A sutura da lesão meniscal é a técnica de escolha no tratamento das lesões instáveis de menisco, em detrimento a uma meniscectomia parcial ou total, preservando o tecido meniscal. ${ }^{1,2}$ Infelizmente, nem todas lesões meniscais podem ser reparadas, especialmente se tiver ocorrido dano extenso no tecido. ${ }^{3,4}$

Após uma meniscectomia, os pacientes geralmente apresentam um período de alívio da dor, mas com o tempo a queixa pode retornar, acompanhada de derrame articular de repetição, principalmente associado a atividades de impacto. Em pacientes jovens e ativos, dor no joelho após meniscectomia pode ser um problema desafiador. ${ }^{4} \mathrm{O}$ transplante meniscal homólogo é uma opção terapêutica para pacientes jovens e ativos que foram submetidos à meniscectomia e apresentam sintomas que limitam suas atividades. ${ }^{3}$

O sucesso do transplante meniscal homólogo depende de diversos fatores. Entre esses fatores temos o armazenamento e disponibilidade dos enxertos. O método de preservação mais utilizado é o congelamento a fresco do menisco., ${ }^{3,5} \mathrm{De}$ acordo com as normas da Agência Nacional de Vigilância Sanitária e do Ministério da Saúde, o tecido meniscal pode permanecer armazenado em banco de tecido por 5 anos até ser transplantado. ${ }^{6}$

Poucos estudos comparam as propriedades histológicas dos meniscos com $<1$ ano de armazenamento com as características dos meniscos armazenados por 5 anos para avaliar se existem alterações significativas nas propriedades biológicas destes enxertos. Nosso objetivo foi comparar as características histológicas do tecido de enxertos meniscais frescos não congelados com as características de meniscos congelados armazenados por 1 mês e meniscos congelados por 5 anos em banco de tecidos.

\section{Material e Método}

Foi feito um estudo histológico com enxertos meniscais armazenados no Banco de Tecidos da nossa instituição. Foram avaliados 10 enxertos meniscais. Dois enxertos permaneceram armazenados, sob congelamento a $-80^{\circ} \mathrm{C}$, no banco de tecidos por 5 anos, outros 4 enxertos permaneceram armazenados, também sob congelamento a $-80^{\circ} \mathrm{C}$, por um período de 1 mês, e outros 4 enxertos foram captados e estudados a fresco. Todos os enxertos incluídos no estudo foram captados de doadores, cujas famílias doaram seus tecidos tanto para transplante quanto para fins de estudo e pesquisa, de acordo com o Termo de Doação preenchido previamente à captação dos órgãos. 0 presente estudo foi aprovado pelo Comitê de Ética em Pesquisa da nossa instituição.

Os meniscos foram enviados ao Departamento de Anatomia Patológica em formol a 10\%, para avaliação das propriedades histológicas dos enxertos e comparação entre os grupos, usando os meniscos frescos não congelados, recém-captados, como parâmetro para comparação com os meniscos armazenados sob congelamento.

Os meniscos foram incluídos em parafina e seccionados em micrótomo rotativo a 5 um de espessura. Foram confeccionadas duas lâminas de cada um dos 10 meniscos, sendo uma amostra obtida através de corte perpendicular na transição entre o corno anterior e o corpo do menisco, e a outra amostra obtida através de corte perpendicular na região do corno posterior. Em todas as 20 amostras, foi obtido tecido tanto da região central quanto da região periférica do menisco.

As amostras foram coradas pelo método de hematoxilina e eosina (H\&E), coloração padrão para avaliação histológica do núcleo, citoplasma e substância fundamental amorfa do tecido, e para complementar a H\&E, foi utilizado o Tricrômico de Masson, método de histoquímica que avalia as 


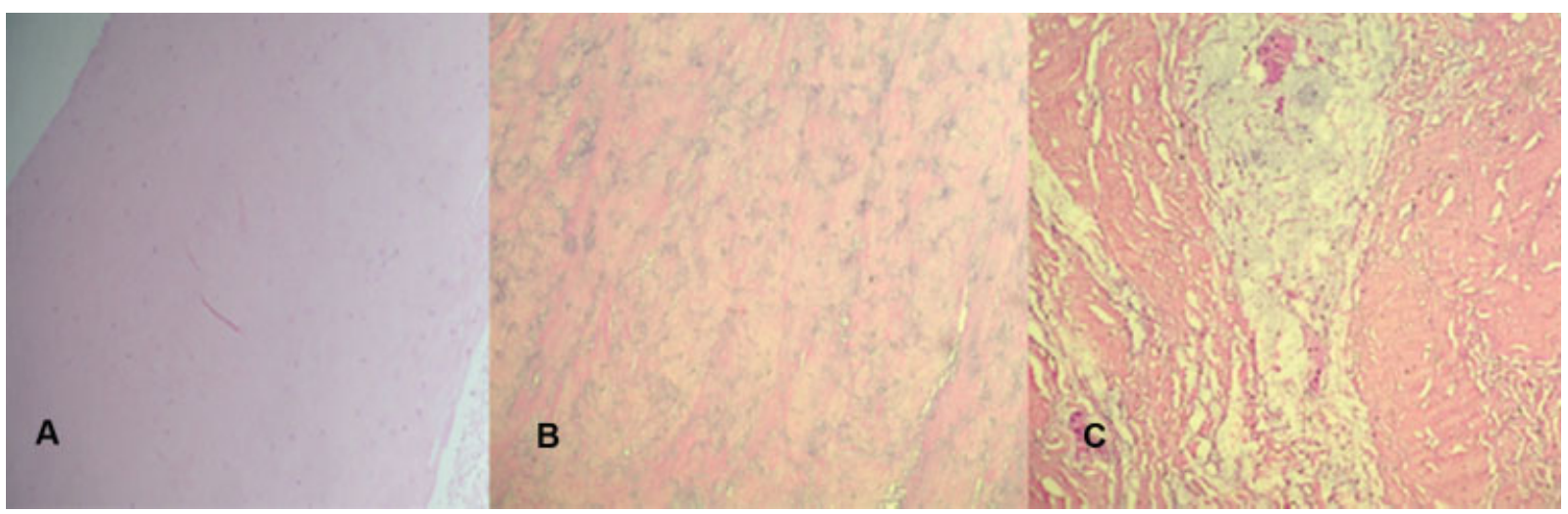

Fig. 1 (A) Menisco a fresco com sua coloração habitual, eosinofílica. (B) Menisco conservado por 1 mês com alteração da cor para basofílica e fragmentação das fibras colágenas. (C) Menisco conservado por 5 anos com alterações mais acentuadas, exibindo extensa degeneração hialina formando acúmulos intersticiais por edema. (Hematoxilina \& Eosina, aumento de 10x).

fibras colágenas. A análise foi realizada pela contagem de pontos aleatórios sobre cada região do menisco, registrando-se os pontos coincidentes sobre condrócitos e fibroblastos/fibrócitos, sendo os resultados expressos, utilizando-se objetiva de 10x, para avaliar a distribuição e a viabilidade celular nas duas regiões, assim como a integridade do tecido fibrocartilaginoso.

\section{Resultados}

Quando comparados com o tecido meniscal fresco não congelado recém-captado, os meniscos que permaneceram congelados por 1 mês apresentaram desorganização parcial da estrutura de suas fibras colágenas, estando estas mais compactas na porção central e com discreta dissociação na porção periférica do menisco, e não houve degeneração hidrópica significativa do tecido. A degeneração do tecido exibia alteração de aspecto basofílico (coloração evidente na hematoxilina). Dois destes meniscos apresentavam condensação e homogeneização das fibras colágenas, enquanto os outros dois apresentavam discreta fragmentação das fibras colágenas, com formação de pequenas áreas vacuolizadas de aspecto hidrópico.
Os meniscos que permaneceram congelados por 5 anos apresentavam alterações mais significativas, cursando com dissociação evidente das fibras colágenas em toda sua extensão, com presença de múltiplos focos de degeneração hidrópica que por vezes formavam acúmulos vacuolares (-Figuras 1 e 2).

\section{Discussão}

O transplante de menisco humano não é mais considerado um tratamento experimental, uma vez que diversos estudos clínicos, com centenas de casos, com alta porcentagem de bons e excelentes resultados, foram publicados sobre o tema na literatura internacional. ${ }^{7-10} \mathrm{O}$ candidato ideal ao transplante meniscal é um paciente ativo, com menos de 50 anos, com membro alinhado, joelho estável, que foi submetido a uma meniscectomia total ou subtotal, e apresenta quadro de dor no compartimento envolvido do joelho, sem alterações degenerativas significativas. ${ }^{3}$

Vários fatores tornam o transplante meniscal homólogo um desafio técnico e logístico. Entre esses fatores temos armazenamento e disponibilidade de enxertos, custos, risco de transmissão de doenças e remodelação do enxerto após a

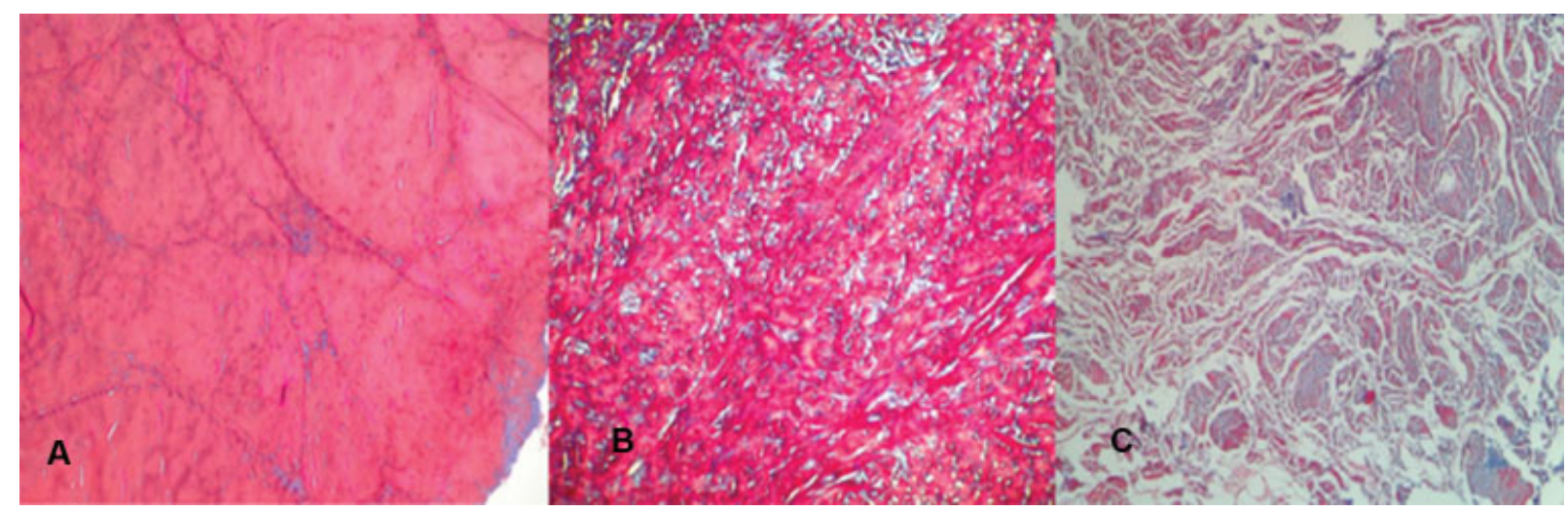

Fig. 2 (A) Menisco a fresco sem fragmentação da fibra. (B) Menisco conservado por 1 mês com descontinuidade das fibras, com acúmulos de material hialino corados em azul. (C) Menisco conservado por 5 anos com fragmentação severa das fibras e acentuada dissociação intersticial por edema. (Tricrômico de Masson, aumento de 10x). 
implantação. ${ }^{3,5}$ Dentre os principais fatores associados à equipe médica temos escolha do tamanho adequado, posicionamento preciso e fixação estável do enxerto meniscal. $^{3,7,9} 0$ enxerto meniscal deve corresponder com precisão às dimensões do joelho receptor para aumentar a chance de restaurar sua função biomecânica normal. ${ }^{11-13} \mathrm{~A}$ implantação adequada do enxerto e sua fixação afetam a função de transmissão de carga ao redor do joelho, e a escolha de um enxerto que corresponda à morfologia do joelho receptor é essencial para otimizar a conformidade entre o menisco e o côndilo femoral. ${ }^{12,14}$

Os quatro métodos de preservação do enxerto descritos são enxerto fresco, congelado fresco, criopreservado e liofilizado. Entretanto, enxertos liofilizados tendem a encolher de maneira significativa após a implantação, e esse método não é mais recomendado como um método de preservação. 0 uso de enxertos frescos apresenta problemas logísticos óbvios, como encontrar um receptor em um período de 7 dias após a captação, antes que se inicie a deterioração celular do enxerto, além do risco aumentado de transmissão de doenças. Enxertos congelados a fresco são os mais utilizados atualmente, com maiores taxas de sucesso, e com o menor risco de transmissão de doenças ou degradação biomecânica. ${ }^{3,5}$

Estudos em animais demonstraram que meniscos transplantados apresentam incorporação e cicatrização adequada na periferia, sem reação inflamatória ou aspecto de rejeição evidente. ${ }^{5,15-17}$ Em nosso meio, Cury et al. ${ }^{17}$ avaliaram a viabilidade de enxertos meniscais congelados transplantados em coelhos. Os autores retiraram o menisco medial de 12 coelhos, mantiveram o menisco congelado à temperatura de - $80^{\circ} \mathrm{C}$ por um período de 30 dias, e reimplantaram o menisco em outro coelho. Após 60 dias, os meniscos foram avaliados do ponto de vista macroscópico e histológico, comparandoos com o grupo controle, que foi o joelho contralateral ileso. Os autores observaram que o menisco congelado transplantado manteve as características biológicas do menisco original em relação ao tamanho e aspecto, apresentando boa cicatrização periférica na membrana sinovial, e não foi observado aspecto de rejeição imunológica.

De acordo com as normas da Agência Nacional de Vigilância Sanitária e do Ministério da Saúde, o tecido meniscal pode permanecer armazenado em banco de tecido por 5 anos até ser transplantado. ${ }^{6} \mathrm{O}$ comportamento biomecânico dos meniscos depende da organização das suas fibras colágenas; dessa forma, o método de preservação ideal não deveria levar a alterações significativas na microestrutura do tecido, independente de sua celularidade. ${ }^{18}$ Em nosso estudo, encontramos degeneração acentuada das propriedades histológicas dos meniscos armazenados sob congelamento por 5 anos, enquanto que os meniscos armazenados congelados por apenas 1 mês apresentavam degeneração mais leve.

Estudos tanto em humanos quanto em animais mostram que o congelamento profundo altera a arquitetura normal das fibras de colágeno, com aumento do conteúdo de água no tecido, de forma semelhante ao que encontramos em nosso estudo. ${ }^{5,16,18-20}$ Gelber et al. ${ }^{19}$ encontraram altera- ções nas fibras colágenas de meniscos armazenados sob congelamento por um período de 7 dias, sugerindo que o congelamento profundo, independente do período de armazenamento, leva a alterações estruturais no enxerto. Em nosso estudo, observamos que mesmo os meniscos armazenados por apenas 1 mês apresentaram alterações em sua arquitetura quando comparados com os meniscos que não foram congelados.

Contudo, a progressão significativa da degeneração do tecido nos tecidos armazenados por período mais longo pode sugerir que o período de 5 anos, considerado período máximo que o enxerto pode permanecer armazenado antes de ser transplantado, é um período muito longo.

Não obstante, os meniscos que permaneceram armazenados por mais tempo tiveram uma degeneração bem mais acentuada, indicando que não apenas o congelamento em si, mas o tempo prolongado de armazenamento sob congelamento leva à progressão significativa da degeneração do tecido meniscal. Nossos achados sugerem que o período de 5 anos, considerado período máximo que o enxerto pode permanecer armazenado antes de ser transplantado, é um período muito longo. Não encontramos nenhuma série de casos de transplante de menisco realizado com enxerto congelado a fresco que descreva o período máximo que os enxertos permaneceram congelados antes do procedimento. Lewis et al. ${ }^{20}$ mostraram em estudo bioquímico, biomecânico e histológico que meniscos submetidos a múltiplos ciclos de congelamento apresentavam diminuição na sua resistência a compressão, com maior desarranjo da sua microestrutura. Verdonk et al. ${ }^{9}$ realizaram sua série de transplante de menisco homólogo com meniscos frescos viáveis não congelados, defendendo que isso não apenas contribui na sobrevivência das células, mas também na produção da matriz extracelular. Apesar dos autores não focarem seus trabalhos no aspecto ultraestrutural dos enxertos, podemos considerar que o uso de enxertos não congelados também apresenta a vantagem de não ocorrer alteração significativa na estrutura das fibras colágenas do tecido meniscal.

A principal limitação do nosso estudo é a amostra reduzida. Nosso fator limitador foi o número pequeno de meniscos no banco de tecidos disponíveis para o estudo. Com nossa amostra, não conseguimos chegar a conclusões definitivas a respeito do período de armazenamento máximo ideal dos tecidos meniscais. Mas levantamos a hipótese que o tempo de 5 anos, aceito atualmente como tempo limite, talvez seja excessivamente prolongado. Mais estudos para avaliar esta hipótese são necessários, além de determinar se as alterações histológicas estão associadas a alterações biomecânicas do tecido. Estudos com uma amostra maior e com análise de um tempo intermediário de armazenamento ( 1 ou 2 anos de congelamento) seriam importantes para responder a pergunta de qual seria o tempo máximo ideal de congelamento.

O tratamento das lesões ligamentares, meniscais e osteocondrais do joelho com enxertos homólogos tem se tornado progressivamente mais popular nas últimas décadas, em todo mundo. A baixa disponibilidade de enxertos nos bancos de tecido musculoesquelético está associada com a dificuldade na popularização dessas técnicas no país. Políticas de 
estímulo para captação e armazenamento de tecido musculoesquelético são fundamentais.

\section{Conclusão}

Os enxertos meniscais armazenados sob congelamento por 1 mês apresentaram discreta alteração degenerativa das fibras colágenas, em quantidade variável, porém sem grandes acúmulos intercelulares. Os meniscos com 5 anos de congelamento apresentaram degeneração significativa do tecido em toda sua extensão, fragmentação e acentuada dissociação das fibras por edema intersticial.

\section{Contribuição dos Autores}

- Netto A. S. - concepção e desenho do trabalho, análise e interpretação dos dados, redação de manuscrito.

- Antebi U. - Análise e interpretação dos dados.

- Morais C. E.- Análise e interpretação dos dados.

- Sementilli L. - Análise e interpretação dos dados.

- Severino N. R. - Revisão crítica do artigo.

- Cury R. P. L. - Revisão crítica do artigo e aprovação final da versão a ser publicada.

Conflito de Interesses

Os autores declaram não haver conflito de interesses.

\section{Referências}

1 Beaufils P, Becker R, Kopf S, Matthieu O, Pujol N. The knee meniscus: management of traumatic tears and degenerative lesions. EFORT Open Rev 2017;2(05):195-203

2 Beaufils P, Pujol N. Management of traumatic meniscal tear and degenerative meniscal lesions. Save the meniscus. Orthop Traumatol Surg Res 2017;103(8S):S237-S244

3 Noyes FR, Heckmann TP, Barber-Westin SD. Meniscus repair and transplantation: a comprehensive update. J Orthop Sports Phys Ther 2012;42(03):274-290

4 Crook TB, Ardolino A, Williams LA, Barlow IW. Meniscal allograft transplantation: a review of the current literature. Ann R Coll Surg Engl 2009;91(05):361-365

5 Samitier G, Alentorn-Geli E, Taylor DC, et al. Meniscal allograft transplantation. Part 1: systematic review of graft biology, graft shrinkage, graft extrusion, graft sizing, and graft fixation. Knee Surg Sports Traumatol Arthrosc 2015;23(01):310-322

6 Brasil. Resolução da Diretoria Colegiada - RDC n 55 de 11/12/2015. Dispõe sobre as Boas Práticas em Tecidos humanos para uso terapêutico. Disponível em: http://portal.anvisa.gov.br/documents/10181/
2718376/RDC_55_2015_.pdf/57eb6007-b35e-4d15-992d-51118 966450c

7 Vundelinckx B, Vanlauwe J, Bellemans J. Long-term subjective, clini$\mathrm{cal}$, and radiographic outcome evaluation of meniscal allograft transplantation in the knee. Am J Sports Med 2014;42(07):1592-1599

8 Zaffagnini S, Grassi A, Marcheggiani Muccioli GM, et al. Survivorship and clinical outcomes of 147 consecutive isolated or combined arthroscopic bone plug free meniscal allograft transplantation. Knee Surg Sports Traumatol Arthrosc 2016;24(05): 1432-1439

9 Verdonk PC, Verstraete KL, Almqvist KF, et al. Meniscal allograft transplantation: long-term clinical results with radiological and magnetic resonance imaging correlations. Knee Surg Sports Traumatol Arthrosc 2006;14(08):694-706

10 Samitier G, Alentorn-Geli E, Taylor DC, et al. Meniscal allograft transplantation. Part 2: systematic review of transplant timing, outcomes, return to competition, associated procedures, and prevention of osteoarthritis. Knee Surg Sports Traumatol Arthrosc 2015;23(01):323-333

11 Kaleka CC, Netto AS, Silva JC, et al. Which are the most reliable methods of predicting the meniscal size for transplantation? Am J Sports Med 2016;44(11):2876-2883

12 Netto ADS, Kaleka CC, Toma MK, et al. Should the meniscal height be considered for preoperative sizing in meniscal transplantation? Knee Surg Sports Traumatol Arthrosc 2018;26(03):772-780

13 Pollard ME, Kang Q, Berg EE. Radiographic sizing for meniscal transplantation. Arthroscopy 1995;11(06):684-687

14 Haut Donahue TL, Hull ML, Rashid MM, Jacobs CR. The sensitivity of tibiofemoral contact pressure to the size and shape of the lateral and medial menisci. J Orthop Res 2004;22(04):807-814

15 Arnoczky SP, DiCarlo EF, O’Brien SJ, Warren RF. Cellular repopulation of deep-frozen meniscal autografts: an experimental study in the dog. Arthroscopy 1992;8(04):428-436

16 Jackson DW, McDevitt CA, Simon TM, Arnoczky SP, Atwell EA, Silvino NJ. Meniscal transplantation using fresh and cryopreserved allografts. An experimental study in goats. Am J Sports Med 1992;20(06):644-656

17 Cury RP, Camargo OP, Prospero JD, et al. Transplante homólogo de menisco: estudo experimental em coelhos. Rev Bras Ortop 2002; 37(08):341-349

18 Gelber PE, Gonzalez G, Torres R, Garcia Giralt N, Caceres E, Monllau JC. Cryopreservation does not alter the ultrastructure of the meniscus. Knee Surg Sports Traumatol Arthrosc 2009;17 (06):639-644

19 Gelber PE, Gonzalez G, Lloreta JL, Reina F, Caceres E, Monllau JC. Freezing causes changes in the meniscus collagen net: a new ultrastructural meniscus disarray scale. Knee Surg Sports Traumatol Arthrosc 2008;16(04):353-359

20 Lewis PB, Williams JM, Hallab N, Virdi A, Yanke A, Cole BJ. Multiple freeze-thaw cycled meniscal allograft tissue: A biomechanical, biochemical, and histologic analysis. J Orthop Res 2008;26(01):49-55 